\title{
The Role of Macrophages in Increased Mitogen Response of Rat Splenic Lymphocytes Following in Vitro Incubation with Vitamin $\mathbf{E}$
}

\author{
Keiko Oonishi, Satoru Moriguchi, ${ }^{*}$ and Yasuo KISHINo \\ Department of Nutrition, School of Medicine, The University of Tokushima, \\ Tokushima 770, Japan
}

(Received March 2, 1995)

\begin{abstract}
Summary The role of macrophages $(\mathrm{M} \varnothing)$ in the enhancement of lymphocyte proliferation by $\alpha$-tocopherol (VE) was investigated using rat splenocytes. The proliferation of whole splenocytes was significantly higher than that of Mø-depleted splenocytes at all concentrations of concanavalin A (Con A; 0.5-10 $\mu \mathrm{g} / \mathrm{ml}$ ). When whole and Mø-depleted splenocytes were preincubated with VE $(2 \mu \mathrm{g} / \mathrm{ml})$ for $24 \mathrm{~h}$, the proliferation of whole splenocytes was significantly enhanced compared to that of whole splenocytes preincubated with medium alone. In contrast, Mødepleted splenocytes did not show any increase of proliferation following in vitro pretreatment with $\mathrm{VE}$. When the splenic Mø pretreated with both VE $(2 \mu \mathrm{g} / \mathrm{ml})$ and Con A $(10 \mu \mathrm{g} / \mathrm{ml})$ for $24 \mathrm{~h}$ were further incubated with splenic lymphocytes, their proliferation was significantly enhanced compared to that of splenic lymphocytes cultured with splenic Mø pretreated with Con A. In this experiment, the medium containing 2-mercaptoethanol (2-ME) had the ability to enhance splenic lymphocyte proliferation, which masked the enhanced effect of VE on splenic lymphocyte proliferation. Furthermore, in vitro treatment of VE could not decrease the production of prostaglandin $\mathrm{E}_{2}$, but could enhance the production of interleukin 1 from splenic Mø. These results suggest that Mø play an important role in the proliferation of splenic lymphocytes following in vitro incubation with VE, which is closely associated with the action of VE as an immunomodulator rather than antioxidant.
\end{abstract}

Key Words vitamin E, lymphocyte proliferation, macrophage, interleukin 1

Previous investigation in our laboratory found that high vitamin E (VE) diets could enhance both splenic lymphocyte and alveolar macrophage (AM) functions in rats (1). Bendich et al. have studied the dietary VE requirement for optimum immune responses (2). Tanaka et al. also found that dietary supplementation of

* To whom correspondence should be addressed. 
VE induced the enhancement of helper T-cell activity in mice (3). It is known that $\mathrm{VE}$ deficiency causes increased production of prostaglandin $\mathrm{E}_{2}\left(\mathrm{PGE}_{2}\right)$, which depresses T-cell functions via an increase in the cellular cAMP level $(4,5)$. Macrophages (Mø) are known to be major prostaglandin (PG)-producing cells and also play a critical role in the regulation of immune responses by releasing monokines which affect lymphocyte functions (6-8). It has been reported that high $\mathrm{VE}$ diet decreases the production of $\mathrm{PGE}_{2}$ from peritoneal $\mathrm{M} \varnothing$ and enhances the cellular immune functions $(1,9)$. However, the precise mechanisms by which VE stimulates lymphocyte proliferation remains unclear. Namely, it is not known whether VE firstly enhances Mø function, and then stimulates lymphocyte proliferation, or whether VE concomitantly stimulates both lymphocyte and Mø functions.

In this experiment, the in vitro effect of VE on the proliferations of both whole splenocytes and macrophage-depleted splenocytes was investigated. In addition, ethanol has been often used in in vitro experiments as a solvent to dilute fat-soluble vitamins (10). However, since it is known that the lower concentrations of ethanol enhance lymphocyte functions (11), VE was diluted with fetal bovine serum (FBS) to avoid the additional effect of ethanol in this experiment.

\section{MATERIALS AND METHODS}

Preparation of splenic lymphocytes. The spleen was removed from male F344 rats, 4 weeks old, obtained from Japan SLC (Shizuoka, Japan) and then minced with scissors. Splenocytes were dissociated by passing through a stainless steel screen. The whole splenocytes were cultured for $1 \mathrm{~h}$ at $37^{\circ} \mathrm{C}$. Then, macrophagedepleted splenic lymphocytes and Mø were separated by adhering to the glass. The rate of $\mathbf{M} \varnothing$ in $\mathbf{M} \varnothing$-depleted splenocytes was less than 5\%, which was checked by nonspecific esterase staining. Both cells were washed with Hanks' balanced salt solution (HBSS) and adjusted to $1 \times 10^{7}$ cells/ml with RPMI 1640 medium containing 5\% FBS.

Dilution of VE. VE ( $\alpha$-tocopherol; Eisai Co. Ltd., Tokyo) was dissolved in FBS by gentle vortexing and incubating in the dark for $20 \mathrm{~min}$ at $37^{\circ} \mathrm{C}$ as described by Narayanareddy and Murthy (12). Then, VE solution was filtered and diluted with RPMI 1640 medium to obtain a final concentration of VE $(2 \mu \mathrm{g} / \mathrm{ml})$. The final concentration of FBS in media with or without VE was $5 \%(\mathrm{v} / \mathrm{v})$.

Proliferation of splenocytes. The response of splenocytes to concanavalin A (Con A) was determined as described previously (13). Whole splenocytes and Mø-depleted splenocytes were co-cultured in the media with or without VE (2 $\mu \mathrm{g} / \mathrm{ml})$ for $72 \mathrm{~h}$ at the various concentrations of Con A $(0-10 \mu \mathrm{g} / \mathrm{ml})$. Then, $1 \mu \mathrm{Ci}$ of $\left[{ }^{3} \mathrm{H}\right]$ thymidine (Specific activity $25 \mathrm{Ci} / \mathrm{mmol}$, New England Nuclear, Boston, MA) was added $20 \mathrm{~h}$ prior to the termination of culture. Their cells were harvested with a Mash II Harvester and the incorporated radioactivity was measured by using a scintillation counter (LSC-703, Aloka Corp., Tokyo). 
Effect of 2-ME on proliferation of splenic lymphocytes. Mø-depleted splenocytes were incubated with Con A $(5 \mu \mathrm{g} / \mathrm{ml})$ in medium containing 2-mercaptoethanol $(2-\mathrm{ME} ; 50 \mu \mathrm{M})$ or VE $(2 \mu \mathrm{g} / \mathrm{ml})$ for $72 \mathrm{~h}$. Then, their proliferation was measured by the incorporation of ${ }^{3} \mathrm{H}$-thymidine.

Interleukin 1 (IL1) production from splenic Mø. IL1 production from splenic $\mathrm{M} \varnothing$ was assessed by proliferation of normal thymocytes from a $\mathrm{C} 3 \mathrm{H} / \mathrm{Hej}$ mouse as described previously (14). Splenic Mø were separated from whole splenocytes by adhesion to glass. From nonspecific esterase staining, the rate of $\mathbf{M} \varnothing$ in isolated cells was $86.4 \pm 6.4 \%$. Their $\mathrm{M} \varnothing\left(1 \times 10^{6}\right.$ cells $\left./ \mathrm{ml}\right)$ were cultured for $24 \mathrm{~h}$ with Con A $(5 \mu \mathrm{g} / \mathrm{ml})$ in the presence or absence of VE $(2 \mu \mathrm{g} / \mathrm{ml})$. The supernatant of these cultures were harvested and used for the assay of IL1 activity. Briefly, thymocytes $\left(1 \times 10^{7} \mathrm{cells} / \mathrm{ml}\right)$ of $\mathrm{C} 3 \mathrm{H} / \mathrm{Hej}$ mouse were incubated with $50 \mu 1$ of their supernatant and $150 \mu 1$ of culture medium for $48 \mathrm{~h}$. Then, their proliferation was measured by the incorporation of ${ }^{3} \mathrm{H}$-thymidine.

$P G E_{2}$ production from splenic $M \varnothing$. Splenic Mø were resuspended in RPMI 1640 medium with 5\% FBS and placed in a flat-bottomed Microtiter plate (Corning Costar Corp., New York) at a density of $5 \times 10^{5}$ cells $/ \mathrm{ml}$. After $24 \mathrm{~h}$, the supernatant were collected and frozen at $-80^{\circ} \mathrm{C}$. The amount of $\mathrm{PGE}_{2}$ in the culture media of splenic Mø incubated with Con A $(5 \mu \mathrm{g} / \mathrm{ml})$ or lipopolysaccharide (LPS; $10 \mu \mathrm{g} / \mathrm{ml}$ ) for $24 \mathrm{~h}$ was determined by the method of Shono et al. (15). Anti-PGE antibody suspension was mixed with $0.1 \mathrm{ml}$ of ${ }^{125} \mathrm{I}$-labeled $\mathrm{PGE}_{2}$. Then, $0.1 \mathrm{ml}$ of either known amounts of $\mathrm{PGE}_{2}$ or supernatant of cultured $\mathrm{M} \varnothing$ was added. After $24 \mathrm{~h}$, immune complexes were precipitated and the amount of $\mathrm{PGE}_{2}$ in the supernate was estimated from standard curve.

Statistical analysis. Experimental results were analyzed by Student's $t$-test (two-tailed).

\section{RESULTS}

Effects of splenic $M \varnothing$ on the proliferation of rat splenocytes following in vitro incubation with various concentrations of Con $A$

Figure 1 shows the effect of $\mathbf{M} \varnothing$ on splenic lymphocyte proliferation following in vitro incubation with various concentrations of Con $A(0-10 \mu \mathrm{g} / \mathrm{ml})$ for $72 \mathrm{~h}$. Proliferation of Mø-depleted splenic lymphocytes was significantly lower at all concentrations of Con A compared to those of whole splenocytes. Maximum proliferation in both whole splenocytes and Mø-depleted splenocytes was shown at $5 \mu \mathrm{g} / \mathrm{ml}$ of Con A.

In vitro effect of $V E$ on the proliferation of whole and Mø-depleted splenocytes following in vitro incubation with Con $A$

The enhancing effect of VE $(2 \mu \mathrm{g} / \mathrm{ml})$ supplementation on splenic lymphocyte proliferation was shown in whole splenocytes, but not in Mø-depleted splenocytes (Fig. 2). When splenic Mø pretreated in vitro with both VE $(2 \mu \mathrm{g} / \mathrm{ml})$ and Con A 


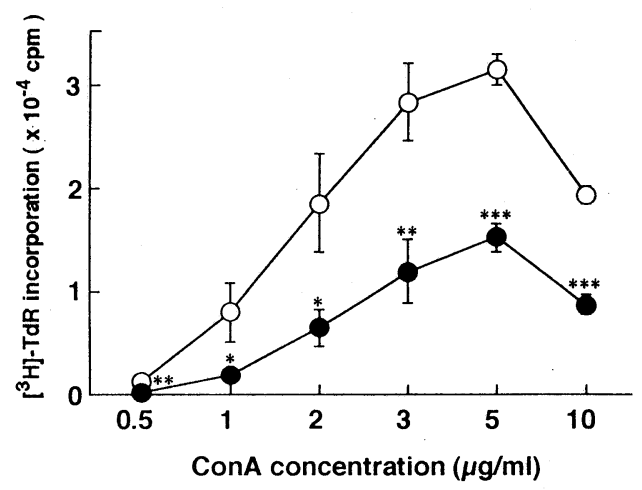

Fig. 1. Proliferations of whole $(\bigcirc)$ and $\mathbf{M} \varnothing$-depleted (๑) splenocytes following in vitro incubation with various concentrations of concanavalin $\mathrm{A}$ (Con A) for 72 h. Significantly different from whole splenocytes; ${ }^{*} p<0.05$, ${ }^{* *} p<0.01,{ }^{* * *} p<$ 0.001 .

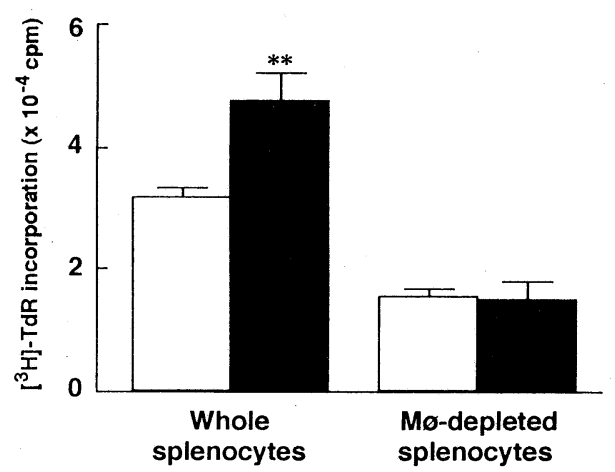

Fig. 2. In vitro effect of vitamin $\mathrm{E}(\mathrm{VE} ; 2 \mu \mathrm{g} / \mathrm{ml})$ on the proliferation of whole and Mø-depleted splenocytes with Con A $(5 \mu \mathrm{g} / \mathrm{ml})$ for $72 \mathrm{~h}$. $\square$, medium;

VE. Significantly different from whole splenocytes incubated with medium alone; ${ }^{* *} p<0.01$.

$(5 \mu \mathrm{g} / \mathrm{ml})$ for $24 \mathrm{~h}$ were added to the culture of splenic lymphocytes without $\mathrm{M} \varnothing$, the proliferation of splenic lymphocytes was also significantly enhanced compared to that of splenic Mø pretreated with Con A only (Fig. 3A).

Effect of 2-mercaptoethanol (2-ME) on the proliferation of splenic lymphocytes following in vitro incubation with Con $A$

In the present experiment, 2-ME was used to increase proliferation of rat splenic lymphocytes in the stimulation with Con $\mathrm{A}$ in vitro. 2-ME may have some effects on the proliferation of splenic lymphocytes cultured with both VE and Con A, as shown in Fig. 2. Then, the effect of 2-ME on the proliferation of splenic lymphocytes was investigated. As shown in Fig. 3B, the proliferation of splenic 

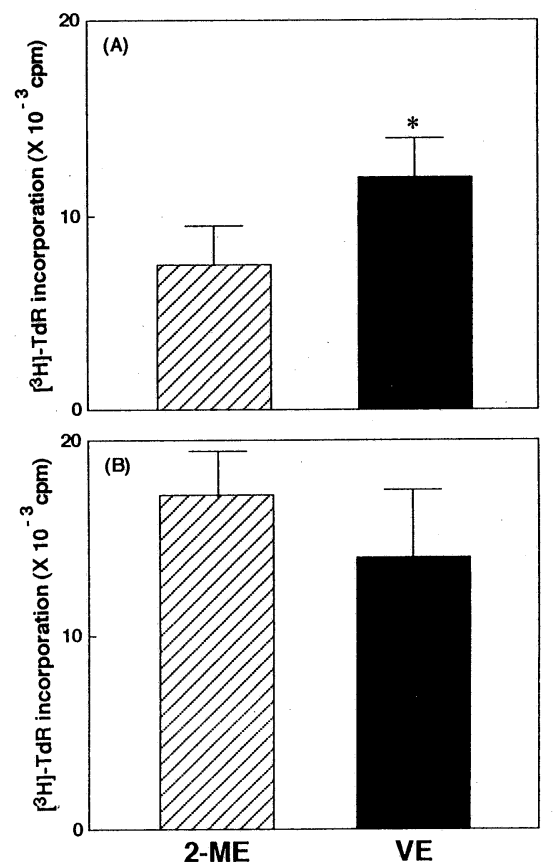

Fig. 3. Effects of 2-mercaptoethanol (2-ME, [Z) and vitamin E (VE, $\square)$ on splenic Mø function (A) and lymphocyte proliferation (B). After splenic Mø were incubated with medium containing 2 -ME $(50 \mu \mathrm{M})$ or VE $(2 \mu \mathrm{g} / \mathrm{ml})$ for 24 $\mathrm{h}$, they were cultured with splenic lymphocytes with Con A $(5 \mu \mathrm{g} / \mathrm{ml})$ for $72 \mathrm{~h}$. The effects of 2-ME and VE on splenic Mø were estimated by the increase of splenic lymphocyte proliferation. $*_{p}<0.05$ (vs. 2-ME). Effects of 2-ME and VE on splenic lymphocyte proliferation were estimated by in vitro stimulation with Con A $(5 \mu \mathrm{g} / \mathrm{ml})$.

lymphocytes incubated in vitro with medium containing $2-\mathrm{ME}(50 \mu \mathrm{M})$ was similar to that of splenic lymphocytes incubated with medium containing VE $(2 \mu \mathrm{g} / \mathrm{ml})$.

Production of ILI and PGE from splenic Mø following in vitro incubation with both $V E$ and ConA for $24 h$

Production of IL1 from splenic Mø was measured by proliferation of mouse thymocytes as described in MATERIALS AND METHODS. As shown in Fig. 4, the supernatant of splenic Mø cultured with both VE $(2 \mu \mathrm{g} / \mathrm{ml})$ and Con A (5 $\mu \mathrm{g} / \mathrm{ml}$ ) for $24 \mathrm{~h}$ significantly enhanced the proliferation of mouse thymocytes compared to that of the supernatant of $M \varnothing$ treated with Con $A(5 \mu \mathrm{g} / \mathrm{ml})$ alone. On the contrary, the production of $\mathrm{PGE}_{2}$ from splenic $\mathrm{M} \varnothing$ was unaffected by in vitro incubation with Con $\mathrm{A}(5 \mu \mathrm{g} / \mathrm{ml})$ for $24 \mathrm{~h}$ and was comparable to that of splenic Mø cultured with medium alone for $24 \mathrm{~h}$ (Fig. 5). Furthermore, in vitro supplementation of VE to the splenic $\mathrm{M} \varnothing$ cultures did not suppress $\mathrm{PGE}_{2}$ produc- 


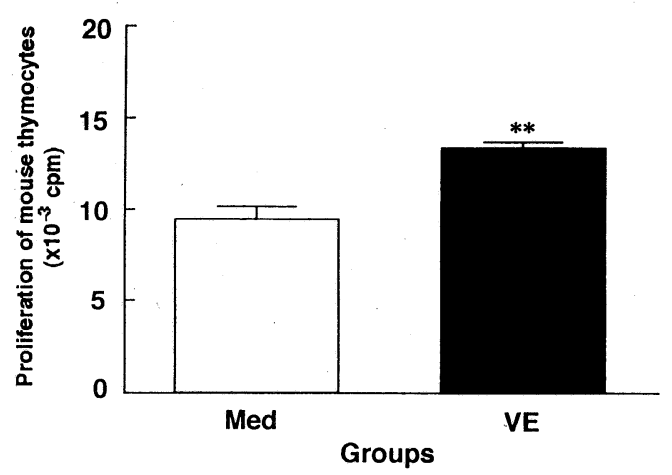

Fig. 4. Proliferation of mouse thymocytes by the supernatant of $\mathrm{M} \varnothing$ cultured with Con A $(5 \mu \mathrm{g} / \mathrm{ml})$ or Con A $(5 \mu \mathrm{g} / \mathrm{ml})+\operatorname{VE}(2 \mu \mathrm{g} / \mathrm{ml})$ for $24 \mathrm{~h}$. $\square$, medium (Stimulation with Con A); Significantly different from medium; ${ }^{* *} p<0.01$.

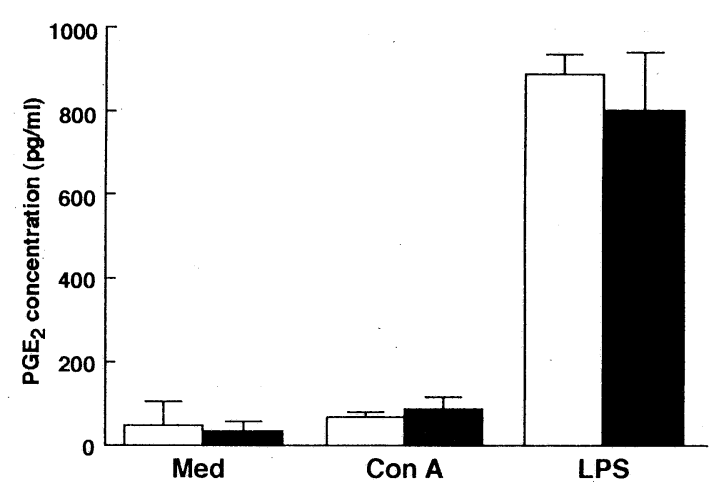

Fig. 5. Effect of VE $(2 \mu \mathrm{g} / \mathrm{ml})$ on $\mathrm{PGE}_{2}$ production from splenic Mø cultured with medium, Con A $(5 \mu \mathrm{g} / \mathrm{ml})$ or LPS $(5 \mu \mathrm{g} / \mathrm{ml})$ for $24 \mathrm{~h}$. $\square$, medium; $\square$, VE.

tion even in Con A stimulation. In the case of in vitro incubation with LPS to induce higher production of $\mathrm{PGE}_{2}$ from splenic $\mathrm{M} \varnothing$, the treatment with VE could not suppress $\mathrm{PGE}_{2}$ production by splenic $\mathrm{Mø}$ (Fig. 5).

\section{DISCUSSION}

In the present study, we found that the proliferation of splenocytes without adherent cells, mainly splenic $\mathrm{M} \varnothing$, is significantly lower than whole splenocytes at all concentrations of Con A, as shown in Fig. 1. This finding agrees with the result of Corwin, et al. (16). Furthermore, they found that the impaired proliferative response of splenic lymphocytes without adherent cells was restored to a considerable degree by the in vitro addition of VE $(1 \mu \mathrm{g} / \mathrm{ml})$. We have also found that the supplementation of VE in vitro could induce a significant increase in splenic 
lymphocyte proliferation with Con A in whole splenocytes, but not in Mø-depleted splenocytes. The discrepancy between the above report and ours may be explained by the difference in the optimum concentration of Con A to induce a higher proliferation of splenic lymphocytes following the depletion of adherent cells (Mø) from whole splenocytes. For instance, the concentration of Con A to induce the maximum proliferation of splenic lymphocytes in whole splenocytes was $5 \mu \mathrm{g} / \mathrm{ml}$. On the contrary, the concentration of Con A in the report of Corwin et al. was $0.125 \mu \mathrm{g} / \mathrm{ml}$, which was considerably lower compared to that of this experiment.

In the next experiment, we investigated whether or not Mø pretreated with both VE $(2 \mu \mathrm{g} / \mathrm{ml})$ and Con A $(5 \mu \mathrm{g} / \mathrm{ml})$ in vitro for $24 \mathrm{~h}$ had the ability to enhance the proliferation of splenic lymphocytes. The addition of splenic Mø pretreated with both VE and Con A to splenic lymphocyte culture could induce even higher proliferation of splenic lymphocytes compared to that of splenic Mø treated with Con A alone as shown in Fig. 3A. This result suggests that VE has the ability to stimulate splenic Mø directly.

Furthermore, there are many reports showing that VE also stimulates lymphocyte functions such as NK activity and mitogenesis $(1,9)$. As shown in Fig. 2, the proliferation of splenic lymphocytes without $\mathbf{M} \varnothing$ had been scarcely increased by in vitro treatment with $\mathrm{VE}$ and was similar to that of splenic lymphocytes cultured with medium alone. Although this result indicates that VE does not stimulate splenic lymphocyte proliferation, it appears that VE has the ability to stimulate the proliferation of splenic lymphocytes as shown in Fig. 3B. In this experiment, the culture medium contained 2-ME. The addition of 2-ME to culture media has been found to enhance the DNA synthetic response of lymphocytes to mitogens $(17,18)$. As shown in Fig. 3B, the addition of 2-ME to the culture media induced a higher proliferation of splenic lymphocytes comparable to that of VE. This result suggests that the action of VE to enhance lymphocyte proliferation may be masked by the addition of 2-ME to the culture media. In addition, since splenic Mø were highly activated by in vitro incubation with VE compared to that of 2-ME as shown in Fig. 3A, VE may activate Mø function as an immunomodulator rather than an antioxidant.

It is known that $\mathrm{M} \varnothing$ are important cells to modulate host immune functions via IL1 and $\mathrm{PGE}_{2}(19,20)$. As shown in Fig. 4, splenic Mø following the in vitro treatment with VE showed significantly higher production of IL1 compared to that of splenic $\mathrm{M} \varnothing$ treated with medium alone. However, the production of $\mathrm{PGE}_{2}$ from splenic $\mathrm{M} \varnothing$ was not increased by in vitro incubation with Con $\mathrm{A}$ and was comparable to that of splenic Mø incubated with medium alone. Meydani et al. have shown that phytohemagglutinin (PHA) induces $\mathrm{PGE}_{2}$ production from peripheral blood mononuclear cells of elderly subjects $(21)$. This conflicts with our finding reported here. The discrepancy is probably due to the difference in the ages of the subjects or animals examined in the experiment, the different stimulating agents used such as PHA and Con A, and the difference of culture condition (the media used in our experiment contained 2-ME). In addition, although $\mathrm{VE}$ is known as a strong 
antioxidant and an inhibitor of prostaglandin synthesis, the addition of VE to the splenic $\mathrm{M} \varnothing$ culture did not decrease the production of $\mathrm{PGE}_{2}$ from splenic $\mathrm{M} \varnothing$ as shown in Fig. 5. This result is in agreement with the report by Sakamoto et al. (22) who found that the addition of VE to the Mø culture had little effect on A23187stimulated $\mathrm{PGE}_{2}$ production. In the case of LPS stimulation, which induces higher production of $\mathrm{PGE}_{2}$ from splenic $\mathrm{M} \varnothing$, in vitro supplementation of VE could not also decrease the production of $\mathrm{PGE}_{2}$ from splenic $\mathrm{M} \varnothing$. Not only higher concentrations of VE ( $>2 \mu \mathrm{g} / \mathrm{ml})$ but also the presence of VE within the cell membrane may be needed to induce the inhibitory effect of $\mathrm{VE}$ on $\mathrm{PGE}_{2}$ production from splenic $\mathrm{M} \varnothing$ (23). Further work is needed to clarify the in vitro effect of VE on the production of $\mathrm{PGE}_{2}$ following stimulation with mitogens.

From the above results, the present study suggests that the action of VE to enhance splenic lymphocyte proliferation with Con $\mathrm{A}$ is mainly mediated by the activation of splenic $\mathbf{M} \varnothing$, which is associated not with decreased production of $\mathrm{PGE}_{2}$, but with increased production of IL1 as an immunomodulator.

\section{REFERENCES}

1) Moriguchi, S., Kobayashi, N., and Kishino, Y. (1990): High dietary intakes of vitamin $\mathrm{E}$ and cellular immune functions in rats. J. Nutr., 120, 1096-1102.

2) Bendich, A., Gabriel, E., and Machlin, L. J. (1986): Dietary vitamin E requirement for optimum immune responses in rats. J. Nutr., 116, 675-681.

3) Tanaka, J., Fujiwara, H., and Torisu, M. (1979): Vitamin E and immune response, enhancement of helper T-cell activity by dietary supplementation of vitamin $\mathrm{E}$ in mice. Immunology, 38, 727-734.

4) Machlin, L. J. (1978): Vitamin E and prostaglandins, in Tocopherol, Oxygen, and Biomembranes, ed. by de Dure, C., and Hayaishi, O., North-Holland Biomedical Press, Amsterdam, pp. 208-215.

5) Meydani, S. N., and Hayek, M. (1992): Vitamin E and the immune response, in Nutrition and Immunology, ed. by Chandra, R. K., ARTS Biomedical Publishers and Distributors, Newfoundland, pp. 105-128.

6) Fidler, I. J. (1985): Macrophages and metastasis-A biological approach to cancer therapy: Presidential address. Cancer Res., 45, 4714-4726.

7) Dempsey, R. A., Dinarello, C. A., Mier, J. W., Rosenwasser, L. J., Allegretta, M., Brown, T. E., and Parkinson, D. R. (1982): The differential effects of human leukocyte pyrogen/lymphocyte-activating factor, $\mathrm{T}$ cell growth factor, and interferon on human natural killer activity. J. Immunol., 129, 2504-2510.

8) Nathan, C. F. (1987): Secretory products of macrophages. Clin. Invest., 79, 319-326.

9) Romach, E. H., Kidao, S., Sanders, B. G., and Kline, K. (1993): Effects of RRR- $\alpha$-tocopheryl succinate on IL-1 and $\mathrm{PGE}_{2}$ production by macrophages. Nutr. Cancer, 20, 205-214.

10) Moriguchi, S., and Kishino, Y. (1990): In vitro activation of tumoricidal properties of human monocytes by $\beta$-carotene encapsulated in liposomes. Nutr. Res., 10, 837-846.

11) Maekawa, K., Moriguchi, S., and Kishino, Y. (1993): In vitro effect of ethanol and acetaldehyde on the functions of splenocytes from rats fed a low protein diet. $A d v$. 
Biosci. 86, 41-46.

12) Narayanareddy, K., and Murthy, P. B. K. (1982): Evidence for cytotoxic effect of vitamin $\mathrm{E}$ on human lymphocytes in vitro. Nutr. Rep. Int., 26, 901-906.

13) Moriguchi, S., Toba, M., and Kishino, Y. (1989): Effect of dietary restriction on cellular immunity in rats. J. Nutr. Sci. Vitaminol., 35, 49-59.

14) Poubelle, P. E., Gingras, D., Demers, C., Dubois, C., Harbour, D., Grassi, J., and Rola-Pleszczynski, M. (1991): Platelet-activating factor (PAF-acether) enhances the concomitant production of tumor necrosis factor-alpha and interleukin-1 by subsets of human monocytes. Immunology, 72, 181-187.

15) Shono, F., Yokota, K., and Yamamoto, S. (1985): A solid-phase enzyme immunoassay thromboxane $\mathrm{B}_{2}$. J. Biochem., 98, 1069-1077.

16) Corwin, L. M., Gordon, R. K., and Shloss, J. (1981): Studies of the mode of action of vitamin E in stimulating T-cell mitogenesis. Scand. J. Immunol., 14, 565-571.

17) Goodman, M. G., and Weigle, W. O. (1977): Nonspecific activation of murine lymphocytes. I. Proliferation and polyclonal activation induced by 2-mercaptoethanol and $\alpha$-thioglycerol. J. Exp. Med., 145, 473-489.

18) Lemke, H., and Opitz, H. G. (1976): Function of 2-mercaptoethanol as a macrophage substitute in the primary immune response in vitro. J. Immunol., 117, 388-395.

19) Plantanias, L. C., and Vogelzang, N. J. (1990): Interleukin-1: Biology, pathophysiology, and clinical prospects. Am. J. Med., 89, 621-629.

20) Goodwin, J. S., Bankhurst, A. D., and Messner, R. P. (1977): Suppression of human T-cell mitogenesis by prostaglandin. Existence of a prostaglandin-producing suppressor cell. J. Exp. Med., 146, 1719-1734.

21) Meydani, S. N., Barklund, M. P., Liu, S., Meydani, M., Miller, R. A., Cannon, J. G., Morrow, F. D., Rocklin, R., and Blumberg, J. B. (1990): Vitamin E supplementation enhances cell-mediated immunity in healthy elderly subjects. Am. J. Clin. Nutr., 52, 557-563.

22) Sakamoto, W., Fujie, K., Handa, H., Nishihara, J., and Mino, M. (1991): Vitamin E inhibits $\mathrm{PGE}_{2}$ and $\mathrm{O}_{2}{ }^{-}$productions in rat peritoneal macrophages. Biochim. Biophys. Acta, 1074, 251-255.

23) Fukuzawa, K., Ikebata, W., Kumadaki, A., Sakanaka, T., and Urano, S. (1992): Location and dynamics of alpha-tocopherol in model phospholipid membranes with different charges. Chem. Phys. Lipids, 63, 69-75. 